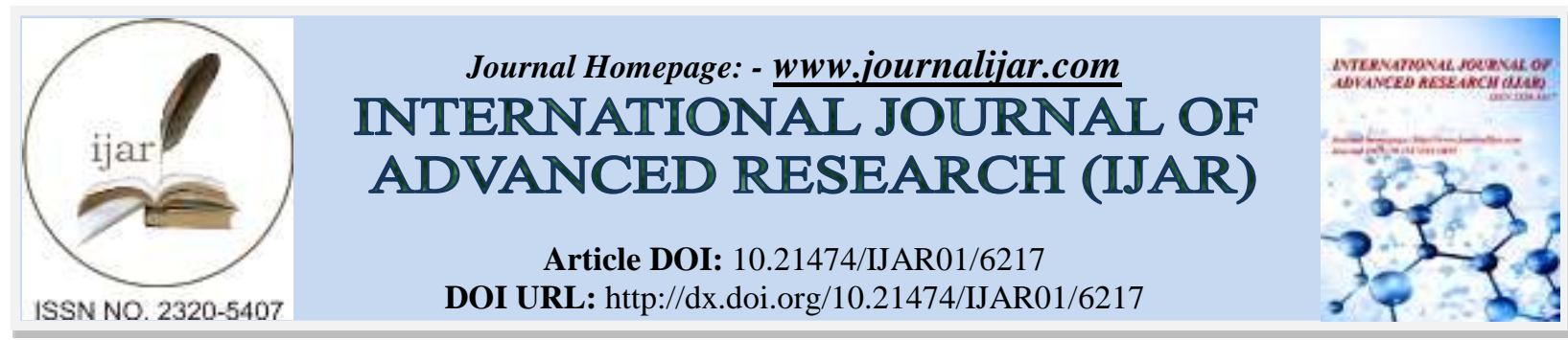

RESEARCH ARTICLE

\title{
AN ECO-FRIENDLY GREEN ROUTE FOR THE SYNTHESIS OF AMIDE FROM CARBOXYLIC ACIDS EMPLOYING MONTMORILLONITE AS A CATALYST.
}

\author{
S. R Jagtap ${ }^{2}$, R. P. Yadav ${ }^{1}$ C. B. Mhaske ${ }^{2}$ and ${ }^{*}$ B. B. Bahule ${ }^{1}$.
}

1. Department of Chemistry, Nowrosjee Wadia College, Pune, Affiliated to Savitribai Phule Pune University, Maharashtra, India.

2. Department of Chemistry, Abeda Inamdar College, Pune, Affiliated to Savitribai Phule Pune University, Maharashtra, India.

\section{Manuscript Info}

Manuscript History

Received: 05 November 2017

Final Accepted: 07 December 2017

Published: January 2018

\section{Key words:-}

Montmorillonite, green route, clay catalyst.

\section{Abstract}

A green protocol for the conversion of organic acids to the corresponding amide is described in this article. The acids are transformed into the amides quantitatively using primary amines and montmorillonite ( K-10) as a clay catalyst. Mixtures of equimolar amounts of acid and primary amine are refluxed in Toluene in presence of small quantity of a catalyst. The reaction completes in 8-9 hours and the catalyst is removed by mere filtration of reaction mixture through whatman filter paper. The removal of solvent furnished crude product, which can be purified if required. The present method is not creating any pollutant during the course of the reaction, hence it follows green route of organic synthesis.

Copy Right, IJAR, 2018,. All rights reserved.

\section{Introduction:-}

Development of new synthetic methods with environment friendly nature is a challenging task in front of organic chemists. Designing pollutant free chemical transformation is the solution to the environmental problems. Carrying out solvent free reactions, reduction in number of steps, avoiding use of corrosive chemicals are some of the remedies in reducing pollution. Use of clay as a catalyst to bring about some organic transformations is important due to following reasons. Clays are nanoparticles with larger structures bearing negative charges. These charges are then balanced by $\mathrm{Na}^{+}, \mathrm{K}^{+}, \mathrm{Ca}^{+}$ions . The $\mathrm{K}-10$ clay is readily available, economical and eco-friendly catalyst made up of alumina-silicates and few cations. Montmorillonite is a clay which can dissociate to give $\mathrm{H}^{+}$ions , hence it is replacing lewis acids effectively ${ }^{1}$. A veriety of organic reactions which are catalysed by Bronsted acids, lewis acids have been shown to take place in clays. The clay provides milder reaction conditions, greater selectivity , better yields and easy recovery of catalyst from the reaction mixture.

The ether synthesis from alcohols ${ }^{2}$, esterification of acids ${ }^{3}$, Diels-Alder reaction ${ }^{4}$, Pinacol-pinacolone rearrangement and many more reactions are known to proceed in the presence of K-10 catalyst. Besides the above reactions number of organic transformations have been carried out in presence of clay. Some of them are pyrrolytic eliminations ${ }^{5}$, oxidation-reduction reactions ${ }^{6}$, formylation of phenols ${ }^{7}$, aldol condensation reaction ${ }^{8}$.

A simple preaparation of amides from acids and amines by heating of their mixture below $200{ }^{\circ} \mathrm{C}$ have been reported by B.S.Jursic and Z.Zdravkovski ${ }^{9}$. Carboxylic acids can be converted into primary amides using urea and imidazole under microwave condition ${ }^{10}$. Amides can be synthesized from aldehydes or imines by vinyl azides ${ }^{11}$. 
Direct amidation of carboxylic acids and interconversion of amides through transmission has been reported by R.M.Langian and T.O.Sheppard ${ }^{12}$. Keeping the available information from the literature we have used K-10 clay as a catalyst for amide preparation from acids and primary amines successfully.

\section{Materials and Methods:-}

The montmorillonite catalyst is procured from and used as it is during the chemical reaction. The toluene is used as a solvent to carry out the reaction. The primary amine is purified prior to the use.

\section{General procedure for the acid to amide conversion:-}

In a $25 \mathrm{ml}$ R.B. flask equipped with a reflux condenser 1 mmole $(1.22 \mathrm{~g})$ of benzoic acid, $1 \mathrm{mmole}(0.093 \mathrm{~g})$ of aniline , $100 \mathrm{mg}$ of K-10 catalyst are placed . $10 \mathrm{ml}$ of toluene was added to the reaction mixture and the mixture was refluxed for 8-9 hours. The course of the reaction mixture was monitored by TLC. Upon the completion of reaction, the reaction mixture was filtered through Whatman filter paper to recover the catalyst. The removal of solvent then furnished the crude amide as a product, which can be purified if necessary. The yields of the products are excellent and there is no formation of undesired side products. The products are characterised by IR and PMR spectroscopy.

\section{Results and Discussion:-}

The findings are summarised in the following result table .

Table 1:-

\begin{tabular}{|l|l|l|l|l|}
\hline Sr.No. & Acid & Primary Amine & $\begin{array}{l}\text { Physical Constant } \\
(\mathrm{MP} / \mathrm{BP}){ }^{0} \mathrm{C}\end{array}$ & $\begin{array}{l}\text { Yield } \\
\text { Amide }\end{array}$ \\
\hline 1 & Benzoic Acid $)$ of \\
\hline 2 & Cinnamic Acid & Aniline & $163-165$ & 78 \\
\hline 3 & p-Toluic Acid & Aniline & $155-157$ & 80 \\
\hline 4 & P-Nitro benzoic Acid & Aniline & $108-110$ & 84 \\
\hline 5 & P-Chlobezoic Acid & Aniline & $218-220$ & 85 \\
\hline
\end{tabular}

\section{Conclusion:-}

The present method provides a green route for the preparation of amides from the organic acids. The un-activated acid can be easily converted into the amides under mild acidic conditions. The clay catalysed reaction does not produce any harmful by-products which is otherwise harmful to the nature. The amide protection is important in case of functional group inter conversion in organic synthesis. The yield of the amides and quality are plus point of this method.

IR data of Benzoic Acid Amide $\left(\mathrm{cm}^{-1}\right)$ 3346, 3056, 1657, 1601, 1530, 1115, 760, 716

PMR data of Benzoic Acid Amide ( ppm ) \{ DMSO - D 6$\}$.

$10.94\{\mathrm{~s}, 1 \mathrm{H}\}, 7.95-7.99\{\mathrm{~m}, 2 \mathrm{H}\}, 7.78-7.81\{\mathrm{~m}, 2 \mathrm{H}\}, 7.52-7.56\{\mathrm{~m}, 3 \mathrm{H}\}, 7.32-7.38\{\mathrm{~m}, 2 \mathrm{H}\}$, 7.07-7.12 \{m, 1H $\}$

The present method is clean and desire products are obtained almost quantitatively. The crude products can be readily by either ether recrystallisation or column chromatographic purification using petroleum ether and ethyl acetate as eluent.

The reaction is not producing any pollutant hence it is environment friendly procedure. The reaction can be performed readily and its non-hazardous nature is very important. The reaction is free of corrosive chemicals hence no specific equipments are needed for it. The products are obtained in high yields.

\section{Acknowledgements:-}

The authors are thankful to the Principal, Nowrosjee Wadia College, Pune for the constant encouragement. We are also thankful to Head, Department of Chemistry, Abeda Inamdar College Pune for providing necessary infrastructure for research work. 


\section{References:-}

1. Gopalpur Nagenrappa .,(2013),Applied Clay Science, 53, 106-138.

2. J.M.Adams, D.F.Clement.,S.H.Graham.,(1982), Clay and clay material, 30,2,129-134.

3. Turnbul and J.C.George.,(1996), Syn.Comm.,26,14,2757-2764.

4. E.Ramesh, R.Ragunathan.,(2009), 26,14,2757-2764.

5. K.G.Nerop, P.F.van Bergan., (2002), Journal of Analytical and Applied Pyrolysis, 63,1,197-208.

6. J.W.Stucki, P.F.Low, C.B.Roth, D.C.Golden.,(1984), Clay and Clay materials,32,5,357-362.

7. F.Bigi,M.L.Conforti,R.Maggi,G.Satori.,(2000), Tetrahedron, 56,17,2709-2712.

8. W.Kagunya, W.Jones., (1995),Applied Clay Science,10,1,95-102.

9. B.G.Jursic, Z. Zdravkovski.,(1993), Synthetic Communication 23,19, 2761-2770.

10. A.K.Neehad,B.Mokhtari, M.N.Soltani Rad.,(2003), Tet.Lett, 44,7325-7328.

11. F.L.Ziang,DR Wang, G.H.Lonca,S.Chiba.,(2014), Angew.Chem,53,17,4390-4394.

12. R.M.Lonigan, T.D.Sheppard.,(2013),European Journal of Organic Chemistry,33,7453-7465. 